\title{
Current evidence for the use of C-MAC videolaryngoscope in adult airway management: a review of the literature
}

This article was published in the following Dove Press journal:

Therapeutics and Clinical Risk Management

3 July 2017

Number of times this article has been viewed

\section{Fu-Shan Xue \\ Hui-Xian Li \\ Ya-Yang Liu \\ Gui-Zhen Yang}

Department of Anesthesiology, Plastic Surgery Hospital, Chinese Academy of Medical Sciences and Peking Union Medical College, Beijing, People's

Republic of China
Correspondence: Fu-Shan Xue Department of Anesthesiology, Plastic Surgery Hospital, Chinese Academy of Medical Sciences and Peking Union Medical College, 33 Ba-Da-Chu Road, Shi-Jing-Shan District, Beijing I00I44, People's Republic of China

Tel +86 I 39 III 7655

Fax +86 108877 2106

Email xuefushan@aliyun.com
Abstract: The C-MAC videolaryngoscope is the first Macintosh-typed videolaryngoscope. Since the advent of its original version video Macintosh system in 1999, this device has been modified several times. A unique feature of C-MAC device is its ability to provide the 2 options of direct and video laryngoscopy with the same device. The available evidence shows that in patients with normal airways, C-MAC videolaryngoscope compared with direct laryngoscopy can provide comparable or better laryngeal views and exerts less force on maxillary incisors, but does not offer conclusive benefits with regard to intubation time, intubation success, number of intubation attempts, the use of adjuncts, and hemodynamic responses to intubation. In patients with predicted or known difficult airways, C-MAC videolaryngoscope can achieve a better laryngeal view, a higher intubation success rate and a shorter intubation time than direct laryngoscopy. Furthermore, the option to perform direct and video laryngoscopy with the same device makes C-MAC videolaryngoscope exceptionally useful for emergency intubation. In addition, the $\mathrm{C}$-MAC videolaryngoscope is a very good tool for tracheal intubation teaching. However, tracheal intubation with C-MAC videolaryngoscope may occasionally fail and introduction of C-MAC videolaryngoscope in clinical practice must be accompanied by formal training programs in normal and difficult airway managements.

Keywords: videolaryngoscopy, direct laryngoscopy, airway management, tracheal intubation, patient safety

\section{Introduction}

In the past decade, videolaryngoscopy-assisted tracheal intubation has extensively been applied in airway management because of several significant advantages. These include: 1) improved laryngeal visualization without the need for aligning 3 airway axes, especially in difficult airway conditions. ${ }^{1}$ 2) The high-quality, magnified airway image makes it easy to identify the airway anatomical structures and anomalies, and facilitates manipulation of airway devices. ${ }^{2} 3$ ) The entire team can see laryngoscopy and intubation process on the monitor, rather than only the intubator. This multi-person visualization feature can facilitate communication and cohesion of team, improve coordination between intubator and assistant, and thus simply change difficult airway management from "I" to "we"., 3,4 Furthermore, the ability of videolaryngoscopy to provide a shared view can make it useful for teaching tracheal intubation. ${ }^{5}$

There are a number of videolaryngoscopes available, with the number constantly increasing and many existing devices being modified. Each device's features may offer advantages or disadvantages, depending on the situations the clinicians have to manage. ${ }^{6}$ Of these devices, videolaryngoscopes with the Macintosh blades can offer 
the unique benefit of both direct and indirect laryngoscopy in a single intubation attempt. A typical example of such a device is C-MAC videolaryngoscope, which is the first Macintosh-type videolaryngoscope, with a great number of publications. This review was aimed to describe the features of C-MAC videolaryngoscope and summarize the evidences regarding efficacy of this device in adult airway management and its role in tracheal intubation teaching according to the literatures published in peer-reviewed journals.

\section{Device description}

C-MAC videolaryngoscope was developed and manufactured by the Karl Storz GmbH \& Co. KG (Tuttlingen, Germany) in 1999. The video Macintosh system in the original model operates with a small color video camera housed to a conventional laryngoscope handle. A Macintosh blade is attached to the handle and a combined image/light bundle is threaded into a small metal guide tube, recessed $40 \mathrm{~mm}$ from the blade tip. The camera cable is attached to a control unit and the light cable to the light source. The video Macintosh system is installed on a small cart so that the device is easily moved. The cart supports an 8-inch monitor mounted on a swivel arm placed on the patient's left side (Figure 1). ${ }^{7,8}$

The modified version of video Macintosh system is the Storz direct-coupled interface, Berci-Kaplan or V-MAC videolaryngoscope, which consists of a laryngoscope, a bulk 8 -inch monitor, a light source and a camera control unit. ${ }^{5}$ A fiber light cord and a camera cable emerge from the top of the handle (Figure 2A), which connect to the light source and the camera control unit, respectively.

The C-MAC or Boedeker-Dörges videolaryngoscope is a modification of the V-MAC device. It includes an

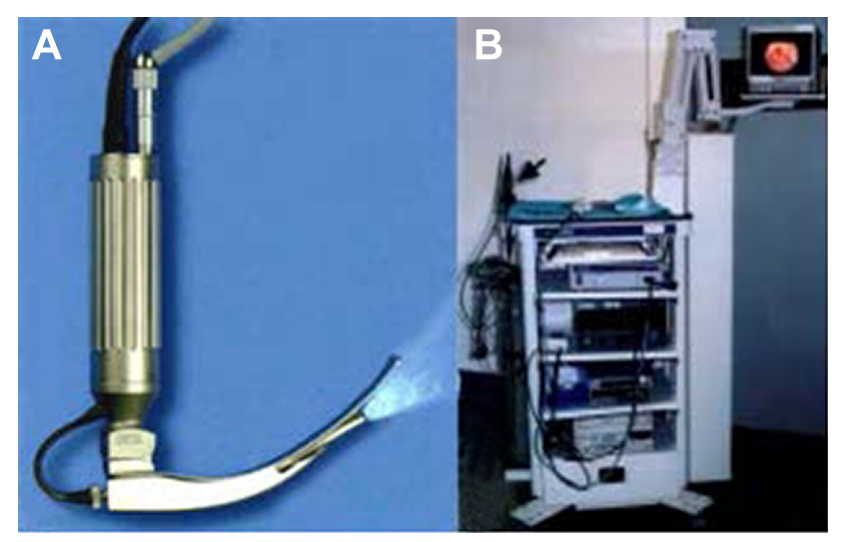

Figure I The video Macintosh system.

Notes: (A) The Macintosh blade is attached to the handle and a combined image/ light bundle is threaded into a small metal guide tube, recessed $40 \mathrm{~mm}$ from the blade tip. (B) The cart that sets the video Macintosh system and hangs an 8-inch monitor. Copyright (C) KARL STORZ GmbH \& Co. KG Germany. ${ }^{80}$ electronic module utilizing semiconductor chip technology and only consists of 3 parts, a laryngoscope, electronic module and separate 7 -in $(18 \mathrm{~cm})$ monitor (Figure $2 \mathrm{~B})$. The monitor connects to the electronic module that plugs into a laryngoscope. The weight of monitor with battery is about $1 \mathrm{~kg}$. The key innovation of C-MAC device is a completely portable setup that features an improved image quality. The main differences between C-MAC and V-MAC devices are that the C-MAC videolaryngoscope includes improved optics, field of view, interface for adjusting video quality, and easy recording of imaging. Moreover, the manufacturer provides the C-MAC device with a 2 -inch pocket monitor attached to the handle (Figure 2C). This portable device is specially developed for pre-hospital and in-hospital first aid. The device incorporates lithium-ion battery technology with at least 2 hours capacity and the pocket monitor can display a clear image under the strong light. ${ }^{1,6-9}$

The C-MAC device can create continuous video recording or static pictures onto a removable secure digital card. ${ }^{8}$ The electronic module includes 2 buttons for photo and video capture. In addition, C-MAC device's images can also be displayed on other devices or recorded by a standard video output port.

There are $3 \mathrm{C}$-MAC reusable metal Macintosh blades (sizes 2-4) available for adult patients. ${ }^{6}$ The reusable blades have a closed design without gaps for hygienic traps and the edges are slanted to avoid tissue damage. ${ }^{10}$ The proximal flange of C-MAC reusable blade is significantly bigger than those of Glidescope and McGrath videolaryngoscopes and is about $2.5 \mathrm{~cm}$ high at its base versus Glidescope videolaryngoscope, which is $1.5 \mathrm{~cm}$ and McGrath videolaryngoscope, which is $1.25 \mathrm{~cm}$. This provides more space for manipulating the tracheal tube with the C-MAC device. In addition, the proximal shape and size of the C-MAC reusable blade make tube passage to the glottis more straightforward compared with that of the Glidescope or McGrath videolaryngoscope. Compared with smaller fanged videolaryngoscopes, however, a disadvantage of the larger proximal flange of C-MAC videolaryngoscope may be the need of a greater mouth opening. ${ }^{11}$

The tip of the C-MAC reusable blade contains a $320 \times 240$ pixel complementary metal oxide semiconductor video chip and fog-resistant lens. The camera with the light source is located close to the tip of the blade and has an $80^{\circ}$ view angle, allowing for a wide angle of viewing at the blade tip and a high-resolution color image on the monitor. ${ }^{8}$ Because the view obtained by C-MAC device includes the blade tip (Figure 2B), it allows for guiding the blade tip into the epiglottic vallecula under vision. ${ }^{10}$ The reusable blades require sterilization between each patient. 

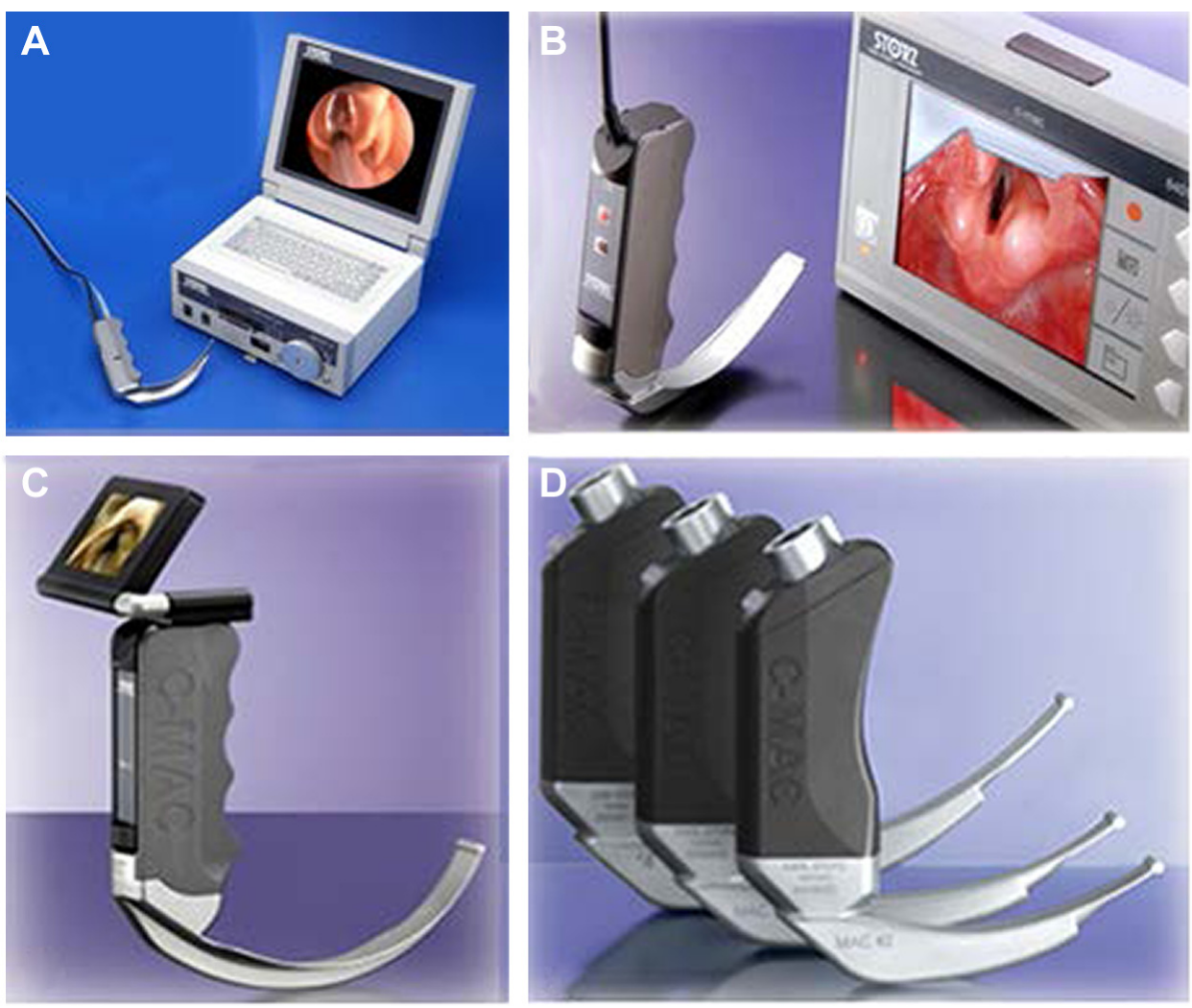

Figure 2 The C-MAC videolaryngoscope system.

Notes: (A) Storz Berci-Kaplan DCl ${ }^{\circledR}$ videolaryngoscope (V-MAC videolaryngoscope); (B) Storz C-MAC videolaryngoscope; (C) portable C-MAC videolaryngoscope with a 2-inch pocket monitor attached to the handle; (D) the latest C-MAC handle with a lightweight and a multifunction interface. Copyright @ KARL STORZ GmbH \& Co. KG Germany. ${ }^{80}$

Recently, the manufacturer has amended the relatively large and bulky handles of C-MAC devices. The new handles are truncated and thinned with a light weight and multifunction C-MAC system interface (Figure 2D). Furthermore, the manufacturer has released the disposable C-MAC device,

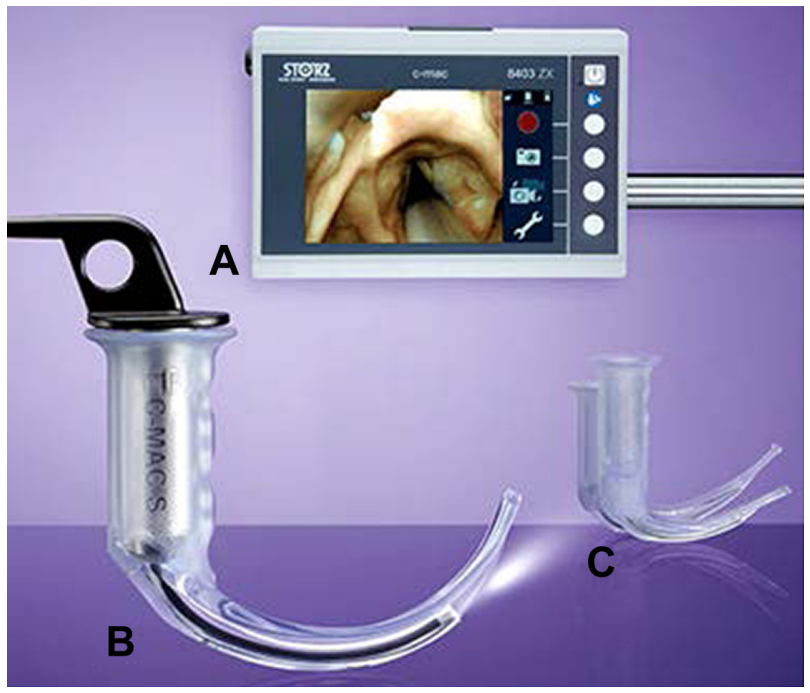

Figure 3 C-MAC videolaryngoscope with disposable plastic blade.

Notes: (A) Video monitor; (B) C-MAC D-Blade videolaryngoscope with disposable plastic blade; (C) disposable Macintosh blade of C-MAC videolaryngoscope. Copyright $\odot$ KARL STORZ GmbH \& Co. KG Germany. ${ }^{80}$ with 2 adult blades (sizes 3 and 4) available (Figure 2D). ${ }^{80}$ The disposable C-MAC device contains a disposable Macintosh plastic blade, an image tube with a camera and a monitor. The image tube is inserted into the disposable plastic blade to be protected from oral contamination. However, the disposable plastic blade is not completely the same as the reusable metal blade. Both the web and flange sections of the disposable plastic blades are significantly thickened to avoid breakage during use. These additional bulk can reduce the pharyngeal view and limit space for manipulating the tracheal tube when using the disposable plastic blade. ${ }^{12}$

As C-MAC videolaryngoscope uses a Macintosh blade, the larynx can be seen either under direct vision or on a monitor. That is, the airway view on the monitor is similar to what is seen when looking directly into the mouth. ${ }^{7}$ Thus, this device is unique among videolaryngoscopes as it allows for use as a videolaryngoscope while simultaneously functioning as a direct laryngoscope. This feature may be useful in the case of video failure or secretions on the lens. ${ }^{6}$ However, a shortcoming of using a Macintosh blade is the frequent needs for alignment of 3 airway axes and external laryngeal pressure to obtain a good laryngeal view during laryngoscopy. 


\section{Intubation procedure with C-MAC videolaryngoscope}

When using as direct laryngoscopy, the intubation procedure with C-MAC videolaryngoscope is identical to conventional Macintosh laryngoscope. The device is inserted into the right side of the mouth, the tongue is moved to the left by the blade flange, the blade tip is advanced into the epiglottic valecula, and then the device is raised to obtain the laryngeal view. ${ }^{11}$ If a poor laryngeal view is obtained, the optimization maneuver includes external laryngeal pressure and blade position adjustment, such as the straight blade technique, to elevate the epiglottis. ${ }^{13}$ Tracheal tube insertion depends on intubator's preference for direct laryngoscopy, when required to use a stylet and the bend angles of the styletted tube. ${ }^{8}$

When using as a videolaryngoscopy, a midline insertion technique without sweep of the tongue can achieve an unobstructed view of the larynx, given the vantage point from beneath the base of the tongue. ${ }^{7}$ Although a stylet is not always required, it can be very helpful for bringing the tube tip up to the glottis, especially in patients with a difficult airway. A study comparing performance of different videolaryngoscopes in patients with a normal airway shows that a stylet is required in $10 \%, 76 \%$ and $60 \%$ of cases with C-MAC, McGrath and Glidescope videolaryngoscopes, respectively. ${ }^{14}$ In patients undergoing elective cervical spine surgery with head and neck stabilized by manual in-line stabilization, the use of stylet significantly reduces the intubation difficulty scale score, intubation time and the use of gum-elastic bougie with C-MAC videolaryngoscope. ${ }^{15}$ When a stylet is used for C-MAC videolaryngoscope, however, a sharp distal bend of the styletted tube is not required as the proximal shape of the blade offers a relatively straighter route for tube insertion, especially in patients with a normal airway. In contrast, sharply-angled videolaryngoscopes, such as Glidescope videolaryngoscopes, a significant distal bend angle of the styletted tube is often required to pass the tracheal tube "around the corner" up to the glottis. ${ }^{11}$

\section{Performance of C-MAC videolaryngoscope versus direct laryngoscopy \\ Normal airways}

The videolaryngoscope was originally designed as a device to manage difficult intubation with direct laryngoscopy. ${ }^{6}$ Although this certainly is true, it misses the point, which limits its use only to the intubations predicted to be difficult or proven difficult after failed intubations with direct laryngoscopy. In fact, success with the application of any device can be enhanced as experience with the intervention accumulates. If videolaryngoscopy is used for all patients, experience and skill would undoubtedly increase, the number of intubation attempts and complications of multiple attempts would decrease, and patient care would improve. ${ }^{4,16}$ It has been suggested that optimal videolaryngoscope should be offered to all patients without significant limitations and not restricted to only those considered most difficult. ${ }^{17}$ In addition, advantages of C-MAC videolaryngoscope combining the benefits of direct and video laryngoscopy in one device also make it suitable to serve as a standard intubation tool for routine airway management. ${ }^{7}$

In available literatures, 3 observational trials comparing direct and indirect (video monitor) laryngeal views using a V-MAC or C-MAC videolaryngoscope in adult patients with a normal airway showed that compared with direct visualization, video-assisted laryngoscopy provided an improved laryngeal view. ${ }^{14,18,19}$ Furthermore, there are several randomized controlled trials (RCTs) comparing the performance of V-MAC or C-MAC videolaryngoscope and direct laryngoscope for orotracheal intubation in adult patients with a normal airway. ${ }^{10,20-25}$ Cavus et $\mathrm{a}^{10}$ found that C-MAC videolaryngoscope provided comparable or better laryngeal views than direct laryngoscopy, and the intubation time was comparable between direct and video laryngoscopy. Sarkılar et $\mathrm{al}^{20}$ compared performance and hemodynamic response to intubation with Macintosh laryngoscope and C-MAC videolaryngoscope and demonstrated that C-MAC device offered a better laryngeal view and a longer intubation time, but the number of intubation attempts, the use of external laryngeal pressure or stylet, and hemodynamic response to orotracheal intubation were comparable between 2 devices. Lee et $\mathrm{al}^{21}$ found that compared with Macintosh laryngoscope, V-MAC device provided a better laryngeal view, required a less number of intubation attempts and a shorter intubation time. In patients who were put in a right lateral position, Bhat et $\mathrm{al}^{22}$ showed that the laryngeal view was improved, intubation time, airway mucosal injury and use of external laryngeal manipulation were reduced with C-MAC videolaryngoscope, but overall success rate of intubation and number of intubation attempts were comparable between C-MAC and Macintosh devices. Three RCTs ${ }^{21,23,24}$ prove that the force exerted on maxillary incisors during laryngoscopy is lower with V-MAC and C-MAC videolaryngoscopes compared with direct laryngoscope. However, a prospective randomized parallel group study confirms that C-MAC videolaryngoscope results in significantly increased hemodynamic responses to intubation than Macintosh laryngoscope. ${ }^{25}$ 
A retrospective analysis compared the double-lumen tube placement using Macintosh laryngoscope and C-MAC videolaryngoscope in patients without predictors of difficult intubation and showed that C-MAC device provided an improved laryngeal view and increased the ease of procedure, but did not offer any benefit on the number of intubation attempts. ${ }^{26}$

\section{Difficult airways}

As the original aim of the videolaryngoscopy design was to solve the main issue of difficult airways, difficult intubation, it has rapidly become a first-line strategy for potential and/or encountered difficult intubation. ${ }^{6}$ Furthermore, most of the current algorithms for difficult airway management recommend videolaryngoscopy as a rescue strategy for difficult or failed intubation with direct laryngoscopy. ${ }^{27-29}$ There have been many studies assessing the application and role of C-MAC videolaryngoscope in difficult airway management.

Two RCTs comparing the effectiveness of V-MAC and C-MAC videolaryngoscopes versus direct laryngoscope for orotracheal intubation in patients with predicted difficult airways demonstrate that videolaryngoscopy provides improved laryngeal views, more successful intubations on the first attempt, shorter laryngoscopy and intubation times, and decreased needs of adjuncts, but did not affect incidence of complications. . $^{30,31}$

The patients with cervical spine injury often require the use of semi-rigid cervical collar or manual in-line stabilization to prevent neck movements, which may lead to poor laryngeal view on direct laryngoscopy and lead to difficulty with intubation. ${ }^{2}$ In patients with a simulated difficult airway by cervical spine immobilization, C-MAC videolaryngoscope compared with direct laryngoscope offers an improved laryngeal view, ${ }^{15,32,33}$ but no conclusive benefits with regard to intubation time, number of intubation attempts, intubation success, and incidence of complications. ${ }^{15,32}$ Furthermore, the tracheal tube placement may occasionally fail despite a good laryngeal view. ${ }^{33}$ In morbidly obese patients, V-MAC or C-MAC videolaryngoscope compared with Macintosh laryngoscope improves the laryngeal view and allows for fast tracheal intubation. ${ }^{34,35}$

In 51 patients with an unexpected Cormack and Lehane grade 3 or 4 view with Macintosh laryngoscope, the laryngeal views are improved and successful intubation is achieved with C-MAC videolaryngoscope in 49 patients (94\%). ${ }^{36}$ In 42 patients whose intubation attempts using Macintosh laryngoscope had failed, C-MAC videolaryngoscope produced improved laryngeal views, achieved a $86 \%$ success rate of intubation at the first attempt and a $100 \%$ total success rate of intubation without severe complications other than minor airway damage. ${ }^{37}$ In a morbidly obese (body mass index [BMI] $36 \mathrm{~kg} / \mathrm{m}^{2}$ ) patient, 3 attempts at Macintosh direct laryngoscopy failed with each resulting in a Cormack-Lehane grade 4 view. ${ }^{38}$ However, tracheal intubation using V-MAC videolaryngoscope was successful on the first attempt. These data provide evidence for the clinical effectiveness of C-MAC videolaryngoscope as an effective rescuing device for unexpected difficult laryngoscopy or failed intubations in routine anesthesia care.

\section{Emergency airways}

Patients requiring tracheal intubations in emergency department, intensive care unit (ICU) and prehospital setting are typical emergency situations associated with hemodynamic compromise and respiratory dysfunction. Due to many reasons, these patients often have a high risk of difficult laryngoscopy and intubation, even when clinicians have adequate airway skills. If inexperienced clinicians are responsible for managing the airway under such challenging conditions, the risk of difficult laryngoscopy and intubation can be further compounded. ${ }^{2}$ Thus, there are increased incidences of failed attempts and complications during emergency intubation compared with elective intubation in the operating room. Furthermore, the complications of emergency intubation have been associated independently with repeated attempts. ${ }^{39}$ Given that the goal of emergency intubation is the first-attempt success, the use of videolaryngoscopy in emergency airway management has significantly increased; it has also been shown to increase intubation success rate at the first attempt. ${ }^{40}$

The option to perform direct and video laryngoscopy with the same device makes C-MAC device exceptionally useful for emergency intubation. In the event of a failed direct laryngoscopy attempt, the intubators can immediately switch to the videolaryngoscopy to successfully complete the intubation without having to make a second attempt, and vice versa ${ }^{41,42}$ Several observational and retrospective studies from emergency department, prehospital and ICU patients showed that a V-MAC or C-MAC device, compared with a direct laryngoscope, was associated with a significantly better visualization of the larynx and a higher proportion of successful intubations, especially for patients with predicted difficult intubations ${ }^{43-47}$ Furthermore, the use of C-MAC videolaryngoscope during emergency intubation was associated with significantly fewer esophageal intubations compared with direct laryngoscopy. ${ }^{43,48,49}$

In a retrospective analysis including 619 consecutive emergency patients, Vassiliadis et $\mathrm{a}^{50}$ found that C-MAC 
videolaryngoscope overall did not provide improved laryngeal views than Macintosh laryngoscope, but it was superior to Macintosh laryngoscope when the CormackLehane grade was at least grade 3; that is, the chance of intubation success was increased by more than 3 -fold by using a C-MAC videolaryngoscope. After the emergency intubation at the first attempt fails, regardless of the initial devices used, C-MAC videolaryngoscope has been shown to be more successful than direct laryngoscope when used for the second attempt. ${ }^{51}$

In the available literature, however, there are the ineffectual outcomes of V-MAC or C-MAC videolaryngoscope in emergency intubation. In the study by Brown et $\mathrm{al}^{46}$ comparing direct and indirect laryngeal views obtained by V-MAC videolaryngoscope, a small percentage of patients (3\%) had worse laryngeal views when switched from direct laryngoscopy to videolaryngoscopy and $6 \%$ of all intubation attempts with videolaryngoscopy failed. A multicenter, observational study by Cavus et $\mathrm{al}^{41}$ evaluating C-MAC videolaryngoscope during prehospital emergency intubation performed by physicians showed a failure rate of $7.5 \%$. In the 2 studies, the reasons for failed videolaryngoscopy included technical problems (monitor malfunctions and low battery) or obstructed views due to airway blood and secretions. Furthermore, tracheal intubation with direct laryngoscopy (using C-MAC blade as a conventional Macintosh blade) is the main rescue measure of a failed videolaryngoscopy. ${ }^{41,46}$

A nonrandomized group-controlled trial comparing C-MAC videolaryngoscope and direct laryngoscope in a critical care transport service demonstrates that the laryngeal view is better with C-MAC device, but number of attempt, first-pass success rate and use of rescue airways are similar between devices. ${ }^{52}$ As yet, there are 3 RCTs that have compared C-MAC videolaryngoscope and direct laryngoscopy for emergency intubation and all of them also show no benefit on intubation success rate and intubation time with the videolaryngoscope. ${ }^{49,53,54}$ In the trial by Sulser et al, ${ }^{53}$ rapid sequence emergency intubation was performed by experienced anesthetists. The results showed that the laryngeal visualization was improved with C-MAC videolaryngoscope, but better laryngeal visualization did not improve intubation success rate at the first attempt and intubation time. The study by Goksu et al, ${ }^{49}$ in which tracheal intubation was performed by emergency residents and attending physicians in the blunt trauma patients, demonstrated that C-MAC videolaryngoscope and direct laryngoscopy were comparable in terms of the overall intubation success rate and intubation time, despite C-MAC device provided the improved laryngeal views. The trial by Driver et $\mathrm{al}^{54}$ in emergency patients did also not detect differences between direct and video laryngoscopy in the intubation success rate at the first attempt, intubation time, aspiration pneumonia, or hospital length of stay when tracheal intubation was performed by senior residents and direct laryngoscopy was used for the first attempt.

Based on available evidence from above studies on emergency intubation, it may be concluded that C-MAC videolaryngoscope can offer improved laryngeal views compared with direct laryngoscopy, but there are conflicting results about whether the improved laryngeal views may result in increased intubation success rate and decreased intubation time. Visualization of the airway on a monitor may be helpful for less experienced intubators in airway management and possibly decreases the rate of esophageal tube misplacements.

\section{Performance of C-MAC videolaryngoscope versus other devices}

There are many videolaryngoscopes available and their efficacies may be different due to their different designs and shapes. To facilitate the suitable choice of these devices for managing various airway conditions, comparing performance of different videolaryngoscopes in patients with diverse conditions is needed. In patients with normal airways requiring orotracheal intubation, Lee et $\mathrm{al}^{55}$ compared the Bonfils intubation fiberscope and C-MAC videolaryngoscope and showed that intubation success rate at the first attempt was not different between the 2 devices, but intubation with C-MAC device required a shorter time, and resulted in significantly attenuated hemodynamic responses. In healthy volunteers undergoing awake upright laryngoscopy, Glidescope videolaryngoscope provides the superior views to C-MAC videolaryngoscope, but laryngoscopy time and number of intubation attempts are similar between devices. ${ }^{56}$

In a prospective RCT performed on patients with predicted difficult airways, Glidescope videolaryngoscope enables significantly better laryngeal views than C-MAC videolaryngoscope, but laryngoscopy time, number of intubation attempts and intubation success rate did not differ between instruments. ${ }^{57} \mathrm{In}$ an $\mathrm{RCT}$ comparing McGrath and C-MAC videolaryngoscopes in adult patients with potential difficult airways, $\mathrm{Ng}$ et $\mathrm{al}^{58}$ found that the C-MAC device allowed a quicker intubation time, a fewer number of intubation attempts and a greater ease of intubation compared with the McGrath device. In patients with cervical spine disorders and immobilization, 
Glidescope and C-MAC videolaryngoscopes provide comparable laryngeal views, but the C-MAC device has a higher first-attempt failure rate, and requires significantly more intubation attempts and optimizing manoeuvers. ${ }^{59}$ Moreover, a RCT trial in obese patients undergoing bariatric surgery shows that V-MAC videolaryngoscope significantly reduces the intubation time compared with the McGrath and Glidescope devices, and requires a fewer number of intubation attempts and a less frequent use of ancillary intubating devices compared to McGrath device. ${ }^{35}$ In addition, a retrospective study comparing Glidescope and C-MAC videolaryngoscopes in patients requiring emergency intubation showed that both the first-pass success rate and overall success rate were similar with 2 devices. ${ }^{60}$

By a prospective, randomized study, Yumul et $\mathrm{al}^{61}$ compared C-MAC videolaryngoscope and flexible fiberoptic scope in patients with cervical spine immobilization and found that the C-MAC device significantly decreased the times required to obtain laryngeal view and successful intubation.

In a multicenter, prospective, non-randomized clinical trial comparing C-MAC and KingVision videolaryngoscopes for prehospital emergency intubation, C-MAC device provides a significantly higher intubation success rate at the first attempt and overall success rate, and needs a less number of intubation attempts, but both the devices are similar in term of intubation complication. ${ }^{62}$

The above findings suggest that when attempting to secure the airway, there is no single device that is better than others in all conditions. Each device has unique properties that may be advantageous in some conditions, but limiting in other situations. ${ }^{6}$ Thus, health care providers involved in airway management must master several different devices. Furthermore, videolaryngoscopes must be selected based on indications. ${ }^{4}$

\section{C-MAC videolaryngoscope and tracheal intubation teaching}

Teaching direct laryngoscopy to the student may be associated with anxiety for both teacher and student. This can be attributed partly to the fact that the teacher cannot see what the intubator is (or is not) visualizing during the procedure. The videolaryngoscopy provides a shared view for both the teacher and student; that is, the high-quality, magnified picture on videolaryngoscopy monitor allows the teacher to explain the anatomy of the upper airway and procedures of laryngoscopy and intubation to student. ${ }^{1}$ Also, when a student is attempting intubation, the teacher can see the monitor and provide a real-time feedback. With videolaryngoscopy, thus, the "peer over my shoulder" teaching method is displaced, and considerable time is saved and many unessential intubation attempts can be avoided. ${ }^{5}$

The C-MAC videolaryngoscope is a very good tool for tracheal intubation teaching, as it has a standard Macintosh blade and thus the intubation procedure is identical to the traditional one. It has been shown that compared with the training with a direct laryngoscope, video-assisted instruction with V-MAC or C-MAC videolaryngoscope may shorten the learning curve of direct laryngoscopy and intubation for students, improve intubation success rate and decrease the rate of esophageal intubation. ${ }^{63,64}$ Following training, the novices trained by using C-MAC videolaryngoscope perform better with respect to number of intubation attempts, number of repositioning maneuvers required and teeth trauma in simulated difficult airway conditions compared with those trained by using Macintosh laryngoscope. ${ }^{65}$ Because of a compact video system, C-MAC videolaryngoscope has also been showed to be well received by the trainees during intubation training in a simulated field hospital setting. ${ }^{66}$

However, a randomized, cross-over study assessing the retention of laryngoscopy skills in medical students shows no significant difference in median intubation time after training between students trained using C-MAC and Macintosh devices, but median intubation time after a brief period of no practice is longer for the students trained by using C-MAC device compared with those trained using the Macintosh device. ${ }^{67}$ This suggests that intubation skill acquisition with C-MAC videolaryngoscope can be achieved after a brief period of learning and practice, but skill maintenance requires regular practice.

\section{Comments}

Videolaryngoscopy creates a visual advantage by placing the intubator's eye near the blade tip, beyond the obstructing anatomy of the upper airway. During the past decade, videolaryngoscopes have been receiving plenty of attention as new airway devices. In current clinical practice, videolaryngoscopy has actually been used in any instance in which tracheal intubation is required and resulted in significant changes in airway management strategy. ${ }^{6}$ Videolaryngoscopy has even been considered a feasible alternative to direct laryngoscopy. ${ }^{4,68}$ Importantly, however, new intubation devices should prove to be at least as safe and more effective than direct laryngoscope to justify the expense of acquisition and the demand that we become proficient with them. 
The available evidence shows that in patients with normal airways, V-MAC or C-MAC videolaryngoscope, compared with direct laryngoscopy, can provide comparable or better laryngeal views and exert less force on maxillary incisors, but does not offer conclusive benefits with regard to intubation time, intubation success, number of intubation attempts, use of adjuncts, and hemodynamic responses to intubation. ${ }^{10,14-26}$ It should be noted that current airway assessment is predicated on difficult intubation with direct laryngoscopy, but a predicated difficult intubation with direct laryngoscopy does not mean that intubation will be difficult with videolaryngoscopy and vice versa.$^{69}$ Furthermore, a good visualization of the larynx during intubation has been shown to directly affect safety and morbidity of patients. ${ }^{70}$ Thus, it is important to have high-performance devices for airway management. Given that C-MAC videolaryngoscope with a standard blade combines the benefits of direct and video laryngoscopy in one device, we agree with other authors that C-MAC videolaryngoscope may serve as a standard intubation device for routine airway management. ${ }^{4,10}$

The benefits of C-MAC videolaryngoscope are most significant in patients with difficult airways, as it can convert "blind" intubations into intubations under visual control. In patients with predicted or known difficult airways, C-MAC device can achieve a better laryngeal view, higher intubation success rate and shorter intubation time than direct laryngoscopy. ${ }^{30,31,34,35}$ Furthermore, C-MAC device has been shown to be an effective rescuing device for unexpectedly difficult laryngoscopy or failed intubations. ${ }^{36-38}$ Thus, C-MAC videolaryngoscope may produce clinically relevant improvement of intubation conditions and can be recommended for difficult airway management. In patients with a difficult airway by cervical spine immobilization, however, the intubation time may be prolonged and tracheal intubation may occasionally fail with C-MAC device despite very good laryngeal visualization. ${ }^{32,33}$ Furthermore, Glidescope videolaryngoscope performs better than C-MAC videolaryngoscope in patients with cervical spine immobilization. ${ }^{59}$ These issues should be noted when a suitable videolaryngoscope for managing a special airway condition is selected.

For emergency airways, most observational and retrospective studies indicate that C-MAC device performs better than direct laryngoscope, especially for patients with a CormackLehane grade 3 or $4 .^{41-48,50,51}$ After a failed first intubation attempt in the emergency department, C-MAC device is more successful at second attempt than the direct laryngoscope. ${ }^{51}$ However, all the available RCTs comparing C-MAC videolaryngoscope and direct laryngoscope for emergency intubation show no benefit on the intubation success rate and intubation time with C-MAC videolaryngoscope. ${ }^{49,53,54}$ The detailed reasons for inconsistent findings obtained from the observational and randomized controlled studies are unclear, but several important issues may be considered. First, observational and retrospective studies have major methodological weaknesses and potentially introduce a number of confounding variables. Second, the patient's position is not clearly descibed in most studies. This may be unimportant for videolaryngoscopy that does not require alignment of the airway axes to expose the larynx. ${ }^{6}$ However, patients' head and neck position can significantly affect performance of direct laryngoscopy that needs to align the airway axes into a more straight line. ${ }^{71}$ Third, most studies require some training and practice with the studied devices prior to the study, but do not give clear definitions of competence with studied devices for intubators. Moreover, most intubations at the first attempt are done by inexperienced intubators. In fact, experience with a standard laryngoscope does not equate skill with a videolaryngoscope. ${ }^{4}$ With videolaryngoscopy, the main challenges for the intubator are to become familiar with the view on the monitor, and coordinate the eyes and hands appropriately. ${ }^{1}$ If intubators have more experience with direct laryngoscopy versus videolaryngoscopy, a higher intubation success rate is associated with former device. If intubators are inexperienced in direct laryngoscopy, videolaryngoscopy may be associated with better intubation success. Thus, the differences in intubation performances between C-MAC videolaryngoscope and direct laryngoscopy in these studies may be contributed to their different learning curves. It has been emphasized that for the results of a comparative study to be valid, participants must be equally proficient with each airway device to avoid bias. ${ }^{72}$ Fourth, the use of neuromuscular blocking agents has been shown to improve the firstattempt success rate of emergency intubation, ${ }^{73,74}$ but this factor is significantly different among studies. Fifth, some studies exclude patients with anticipated or known difficult airways, though C-MAC videolaryngoscope is more effective than direct laryngoscopy for such conditions..$^{50,51}$

It must be emphasized that when considering the role of C-MAC videolaryngoscope in securing an airway for patients requiring emergency intubation, an important fact that a device can provide 2 options of direct and video laryngoscopy cannot be neglected. That is, when one option at the first attempt fails, the intubators can immediately switch to another option to successfully complete the intubation without having to make a second attempt. ${ }^{41,42}$ This unique feature of C-MAC device is significantly different from 
the angulated videolaryngoscopes, such as C-MAC D-Blade and Glidescope devices which can only provide the videolaryngoscopic option. Given that no algorithm can reliably predict the difficult emergency intubation with direct or video laryngoscopy prior to intubation and emergency patients do not allow multiple intubation attempts, ${ }^{50,51,75}$ we argue that the use of C-MAC videolaryngoscope with 2 options as a main device for emergency intubation may be a safe procedure and should be used as the first-line device in all emergency intubations. A recent meta-analysis of observational, retrospective and randomized data comparing video versus direct laryngoscopy for orotracheal intubation in the ICU patients shows that the first-attempt success is twice as likely to occur with the use of a videolaryngoscope. ${ }^{40}$ Furthermore, a largest propensity-matched analysis comparing video and direct laryngoscopy in the ICU to date demonstrates a higher odds of first-attempt success and a lower incidence of complications with videolaryngoscopy. ${ }^{76}$ Thus, some emergency medicine airway experts have called that videolaryngoscopy should replace direct laryngoscopy for tracheal intubation in all emergency patients. ${ }^{16,50,51,68,77,78}$

However, clinicians should bear in mind that no single device can offer a solution to all airway conditions. The C-MAC videolaryngoscope provides a high intubation success rate, but does not give a $100 \%$ success rate. ${ }^{33,41,46}$ To manage airway conditions expeditiously and safely, the practitioners must master the several different airway devices and techniques. Furthermore, any difficult airway management strategy, including videolaryngoscopes must include a contingency plan for failure. ${ }^{79}$

Finally, there are some limitations of this review. First, there are high heterogeneity among included studies, such as levels of intubators' experience and skill with the studied devices, intubation strategies and definitions of primary outcomes. Second, none of the RCTs included in this review is a double-blinded study because it is impossible to make the intubators unaware of the devices they would use for intubation. Third, most of the studies have a small sample size and patients have different airway conditions. Fourth, many studies on difficult and emergency intubations only assess differences in intubation variables between C-MAC videolaryngoscope and direct laryngoscope, but do not evaluate the clinical outcomes, such as morbidity and mortality of patients. Thus, it is unclear whether favorable effect of C-MAC videolaryngoscope on intubation outcomes can be translated to clinical benefits. These factors may complicate the interpretation for clinical performance of C-MAC videolaryngoscope.

\section{Conclusion}

A unique feature of C-MAC videolaryngoscope with a Macintosh blade is its ability to provide both the options of direct and video laryngoscopy in the same device. It makes the use of C-MAC videolaryngoscope very appealing. As yet, the roles of C-MAC videolaryngoscope in airway management and education have been well established by published literatures. The available evidence supports that C-MAC videolaryngoscope can be used as a primary intubation tool, particularly when the intubators have less experience of airway management and preoperative airway screening suggests intubation difficulty. It may improve patient safety by avoiding unnecessary intubation attempts and facilitate learning of both direct and video laryngoscopy. Thus, the advent of C-MAC videolaryngoscope expands the armamentarium for health care providers who are involved in airway management. However, the biggest impediment to the widespread use of this device is likely to be the cost, as it is one of currently most expensive videolaryngoscopes. Furthermore, the introduction of C-MAC device in clinical practice must be accompanied by formal training programs in normal and difficult airway managements.

\section{Authors' contribution}

FS Xue made substantial contributions to acquisition of data and interpretation of data, drafted and revised this manuscript, and is responsible for this manuscript. HX Li, YY Liu and GZ Yang made substantial contributions to acquisition of data and interpretation of data, and helped write the manuscript. All authors had read and approved the final manuscript.

\section{Disclosure}

The authors report no conflicts of interest in this work.

\section{References}

1. Niforopoulou P, Pantazopoulos I, Demestiha T, Koudouna E, Xanthos T. Video-laryngoscopes in the adult airway management: a topical review of the literature. Acta Anaesthesiol Scand. 2010;54(9):1050-1061.

2. Maldini B, Hodžović I, Goranović T, Mesarić J. Challenges in the use of video laryngoscopes. Acta Clin Croat. 2016;55 (Suppl 1):41-50.

3. Paolini JB, Donati F, Drolet P. Review article: video-laryngoscopy: another tool for difficult intubation or a new paradigm in airway management? Can J Anesth. 2013;60(2):184-191.

4. Kelly FE, Cook TM. Seeing is believing: getting the best out of videolaryngoscopy. Br J Anaesth. 2016;117 (Suppl 1):9-13.

5. Kaplan MB, Ward DS, Berci G. A new video laryngoscope-an aid to intubation and teaching. J Clin Anesth. 2002;14(8):620-626.

6. Xue FS, Liu QJ, Li HX, Liu YY. Videolaryngoscopy assisted intubation-new era for airway management. J Anesth Perioper Med. 2016;3(6):258-269.

7. Aziz M, Brambrink A. The Storz C-MAC video laryngoscope: description of a new device, case report, and brief case series. J Clin Anesth. 2011; 23(2):149-152. 
8. Green-Hopkins I, Nagler J. Endotracheal intubation in pediatric patients using video laryngoscopy: an evidence-based review. Pediatr Emerg Med Pract. 2015;12(8):1-22.

9. Holm-Knudsen R. The difficult pediatric airway-a review of new devices for indirect laryngoscopy in children younger than two years of age. Pediatr Anesth. 2011;21(3):98-103.

10. Cavus E, Thee C, Moeller T, Kieckhaefer J, Doerges V, Wagner K. A randomized, controlled crossover comparison of the C-MAC videolaryngoscope with direct laryngoscopy in 150 patients during routine induction of anesthesia. BMC Anesthesiol. 2011;11:6.

11. Levitan RM, Heitz JW, Sweeney M, Cooper RM. The complexities of tracheal intubation with direct laryngoscopy and alternative intubation devices. Ann Emerg Med. 2011;57(3):240-247.

12. Greenland KB. Disposable C-MAC ${ }^{\circledR}$ videolaryngoscope blade-not the same as the re-usable blade. Anesthesia. 2014;69(12):1402-1403.

13. Cavus E, Kieckhaefer J, Doerges V, Moeller T, Thee C, Wagner K. The C-MAC videolaryngoscope: first experiences with a new device for videolaryngoscopy-guided intubation. Anesth Analg. 2010;110(2): 473-477.

14. van Zundert A, Maassen R, Lee R, et al. A Macintosh laryngoscope blade for videolaryngoscopy reduces stylet use in patients with normal airways. Anesth Analg. 2009;109(3):825-831.

15. Gupta N, Rath GP, Prabhakar H. Clinical evaluation of C-MAC videolaryngoscope with or without use of stylet for endotracheal intubation in patients with cervical spine immobilization. J Anesth. 2013;27(5): 663-670.

16. Brown CA 3rd, Pallin DJ, Walls RM. Video laryngoscopy and intubation safety: the view is becoming clear. Crit Care Med. 2015;43(3):717-718.

17. Agro FE, Doyle DJ, Vennari M. Use of GlideScope ${ }^{\circledR}$ in adults: an overview. Minerva Anestesiol. 2015;81(3):342-351.

18. Kaplan MB, Hagberg CA, Ward DS, et al. Comparison of direct and video-assisted views of the larynx during routine intubation. J Clin Anesth. 2006;18(5):357-362.

19. Shimada N, Mogi K, Niwa Y, et al. The C-MAC videolaryngoscope: its utility in tracheal intubation by novice personnel. Masui. 2012; 61(6):649-452.

20. Sarkılar G, Sargın M, Sarıtaş TB, et al. Hemodynamic responses to endotracheal intubation performed with videoand direct laryngoscopy in patients scheduled for major cardiac surgery. Int J Clin Exp Med. 2015;8(7):11477-11483.

21. Lee RA, van Zundert AA, Maassen RL, Wieringa PA. Forces applied to the maxillary incisors by video laryngoscopes and the Macintosh laryngoscope. Acta Anaesthesiol Scand. 2012;56(2):224-229.

22. Bhat R, Sanickop CS, Patil MC, Umrani VS, Dhorigol MG. Comparison of Macintosh laryngoscope and C-MAC video laryngoscope for intubation in lateral position. J Anaesthesiol Clin Pharmacol. 2015; 31(2):226-229.

23. Pieters B, Maassen R, Van Eig E, Maathuis B, Van Den Dobbelsteen J, Van Zundert A. Indirect videolaryngoscopy using Macintosh blades in patients with non-anticipated difficult airways results in significantly lower forces exerted on teeth relative to classic direct laryngoscopy: a randomized crossover trial. Minerva Anestesiol. 2015; 81(8):846-854.

24. Lee RA, van Zundert AA, Maassen RL, et al. Forces applied to the maxillary incisors during video-assisted intubation. Anesth Analg. 2009;108(1):187-191.

25. Buhari FS, Selvaraj V. Randomized controlled study comparing the hemodynamic response to laryngoscopy and endotracheal intubation with McCoy, Macintosh, and C-MAC laryngoscopes in adult patients. J Anaesthesiol Clin Pharmacol. 2016;32(4):505-509.

26. Purugganan RV, Jackson TA, Heir JS, Wang H, Cata JP. Video laryngoscopy versus direct laryngoscopy for double-lumen endotracheal tube intubation: a retrospective analysis. J Cardiothorac Vasc Anesth. 2012;26(5):845-848.

27. Apfelbaum JL, Hagberg CA, Caplan RA, et al. Practice guidelines for management of the difficult airway: an updated report by the American Society of Anesthesiologists Task Force on Management of the Difficult Airway. Anesthesiology. 2013;118(2):251-270.
28. Frerk C, Mitchell VS, McNarry AF, et al. Difficult Airway Society 2015 guidelines for management of unanticipated difficult intubation in adults. Br J Anaesth. 2015;115(6):827-848.

29. Japanese Society of Anesthesiologists. JSA airway management guideline 2014: to improve the safety of induction of anesthesia. J Anesth. 2014;28(4):482-493.

30. Jungbauer A, Schumann M, Brunkhorst V, Börgers A, Groeben H. Expected difficult tracheal intubation: a prospective comparison of direct laryngoscopy and video laryngoscopy in 200 patients. $\mathrm{Br} \mathrm{J}$ Anaesth. 2009;102(4):546-550.

31. Aziz MF, Dillman D, Fu R, Brambrink AM. Comparative effectiveness of the C-MAC video laryngoscope versus direct laryngoscopy in the setting of the predicted difficult airway. Anesthesiology. 2012;116(3): 629-636.

32. Byhahn $\mathrm{C}$, Iber $\mathrm{T}$, Zacharowski $\mathrm{K}$, et al. Tracheal intubation using the mobile C-MAC video laryngoscope or direct laryngoscopy for patients with a simulated difficult airway. Minerva Anestesiol. 2010; 76(8):577-583.

33. Akbar SH, Ooi JS. Comparison between C-Mac video-laryngoscope and Macintosh direct laryngoscope during cervical spine immobilization. Middle East J Anaesthesiol. 2015;23(1):43-50.

34. Gaszyński T. Clinical experience with the C-Mac videolaryngoscope in morbidly obese patients. Anaesthesiol Intensive Ther. 2014; 46(1):14-16.

35. Yumul R, Elvir-Lazo OL, White PF, et al. Comparison of three video laryngoscopy devices to direct laryngoscopy for intubating obese patients: a randomized controlled trial. J Clin Anesth. 2016;31:71-77.

36. Piepho T, Fortmueller K, Heid FM, Schmidtmann I, Werner C, Noppens RR. Performance of the C-MAC video laryngoscope in patients after a limited glottic view using Macintosh laryngoscopy. Anesthesia. 2011;66(12):1101-1105.

37. Kilicaslan A, Topal A, Tavlan A, Erol A, Otelcioglu S. Effectiveness of the C-MAC video laryngoscope in the management of unexpected failed intubations. Braz J Anesthesiol. 2014;64(1):62-65.

38. Maassen R, Lee R, van Zundert A, Cooper R. The videolaryngoscope is less traumatic than the classic laryngoscope for a difficult airway in an obese patient. J Anesth. 2009;23(3):445-448.

39. Cook TM, Woodall N, Harper J, Benger J. Major complications of airway management in the UK: results of the Fourth National Audit Project of the Royal College of Anesthetists and the Difficult Airway Society. Part 2: intensive care and emergency departments. Br J Anaesth. 2011;106(5):632-642.

40. De Jong A, Molinari N, Conseil M, et al. Video laryngoscopy versus direct laryngoscopy for orotracheal intubation in the intensive care unit: a systematic review and meta analysis. Intensive Care Med. 2014;40(5):629-639.

41. Cavus E, Callies A, Doerges V, et al. The C-MAC videolaryngoscope for prehospital emergency intubation: a prospective, multicentre, observational study. Emerg Med J. 2011;28(8):650-653.

42. Sakles JC, Mosier JM, Patanwala AE, Arcaris B, Dicken JM. The Utility of the C-MAC as a Direct Laryngoscope for Intubation in the Emergency Department. J Emerg Med. 2016;51(4):349-357.

43. Sakles JC, Mosier J, Chiu S, Cosentino M, Kalin L. A comparison of the C-MAC video laryngoscope to the Macintosh direct laryngoscope for intubation in the emergency department. Ann Emerg Med. 2012;60(6):739-748.

44. Noppens RR, Geimer S, Eisel N, David M, Piepho T. Endotracheal intubation using the C-MAC video laryngoscope or the Macintosh laryngoscope: a prospective, comparative study in the ICU. Crit Care. 2012;16(3):R103.

45. Hossfeld B, Frey K, Doerges V, Lampl L, Helm M. Improvement in glottic visualization by using the C-MAC PM videolaryngoscope as a first-line device for out-of-hospital emergency tracheal intubation: An observational study. Eur J Anaesthesiol. 2015;32(6):425-431.

46. Brown CA 3rd, Bair AE, Pallin DJ, Laurin EG, Walls RM; National Emergency Airway Registry (NEAR) Investigators. Improved glottic exposure with the Video Macintosh Laryngoscope in adult emergency department tracheal intubations. Ann Emerg Med. 2010;56(2):83-88. 
47. Jones BM, Agrawal A, Schulte TE. Assessing the efficacy of video versus direct laryngoscopy through retrospective comparison of 436 emergency intubation cases. J Anesth. 2013;27(6):927-930.

48. Sakles JC, Javedani PP, Chase E, Garst-Orozco J, Guillen-Rodriguez JM, Stolz U. The use of a video laryngoscope by emergency medicine residents is associated with a reduction in esophageal intubations in the emergency department. Acad Emerg Med. 2015;22(6):700-707.

49. Goksu E, Kilic T, Yildiz G, Unal A, Kartal M. Comparison of the C-MAC video laryngoscope to the Macintosh laryngoscope for intubation of blunt trauma patients in the ED. Turk J Emerg Med. 2016; 16(2):53-56.

50. Vassiliadis J, Tzannes A, Hitos K, Brimble J, Fogg T. Comparison of the C-MAC video laryngoscope with direct Macintosh laryngoscopy in the emergency department. Emerg Med Australas. 2015;27(2):119-125.

51. Sakles JC, Mosier JM, Patanwala AE, Dicken JM, Kalin L, Javedani PP. The C-MAC video laryngoscope is superior to the direct laryngoscope for the rescue of failed first-attempt intubations in the emergency department. J Emerg Med. 2015;48(3):280-286.

52. Guyette FX, Farrell K, Carlson JN, Callaway CW, Phrampus P. Comparison of video laryngoscopy and direct laryngoscopy in a critical care transport service. Prehosp Emerg Care. 2013;17(2):149-154.

53. Sulser S, Ubmann D, Schlaepfer M, et al. C-MAC videolaryngoscope compared with direct laryngoscopy for rapid sequence intubation in an emergency department: a randomized clinical trial. Eur J Anaesthesiol. 2016;33(12):943-948.

54. Driver BE, Prekker ME, Moore JC, Schick AL, Reardon RF, Miner JR. Direct versus video laryngoscopy using the C-MAC for tracheal intubation in the emergency department, a randomized controlled trial. Acad Emerg Med. 2016;23(4):433-439.

55. Lee AH, Nor NM, Izaham A, Yahya N, Tang SS, Manap NA. Comparison of the Bonfils intubation fibrescope versus C-MAC videolaryngoscope. Middle East J Anaesthesiol. 2016;23(5):517-525.

56. Drenguis AS, Carlson JN. GlideScope versus. C-MAC for awake upright laryngoscopy. J Emerg Med. 2015;49(3):361-368.

57. Serocki G, Bein B, Scholz J, Dörges V. Management of the predicted difficult airway: a comparison of conventional blade laryngoscopy with video-assisted blade laryngoscopy and the GlideScope. Eur $J$ Anaesthesiol. 2010;27(1):24-30.

58. Ng I, Hill AL, Williams DL, Lee K, Segal R. Randomized controlled trial comparing the McGrath videolaryngoscope with the C-MAC videolaryngoscope in intubating adult patients with potential difficult airways. Br J Anaesth. 2012;109(3):439-443.

59. Brück S, Trautner H, Wolff A, et al. Comparison of the C-MAC and GlideScope videolaryngoscopes in patients with cervical spine disorders and immobilization. Anesthesia. 2015;70(2):160-165.

60. Mosier J, Chiu S, Patanwala AE, Sakles JC. A comparison of the GlideScope video laryngoscope to the C-MAC videolaryngoscope for intubation in the emergency department. Ann Emerg Med. 2013; 61(4):414-420.

61. Yumul R, Elvir-Lazo OL, White PF, et al. Comparison of the C-MAC video laryngoscope to a flexible fiberoptic scope for intubation with cervical spine immobilization. J Clin Anesth. 2016;31:46-52.

62. Burnett AM, Frascone RJ, Wewerka SS, et al. Comparison of success rates between two video laryngoscope systems used in a prehospital clinical trial. Prehosp Emerg Care. 2014;18(2):231-238.
63. Howard-Quijano KJ, Huang YM, Matevosian R, Kaplan MB, Steadman RH. Video-assisted instruction improves the success rate for tracheal intubation by novices. Br J Anaesth. 2008;101(4):568-572.

64. Herbstreit F, Fassbender P, Haberl H, Kehren C, Peters J. Learning endotracheal intubation using a novel videolaryngoscope improves intubation skills of medical students. Anesth Analg. 2011;113(3):586-590.

65. Low D, Healy D, Rasburn N. The use of the BERCI DCI Video Laryngoscope for teaching novices direct laryngoscopy and tracheal intubation. Anesthesia. 2008;63(2):195-201.

66. Boedeker BH, Bernhagen MA, Miller DJ, Miljkovic N, Kuper GM, Murray WB. Field use of the STORZ C-MAC video laryngoscope in intubation training with the Nebraska National Air Guard. Stud Health Technol Inform. 2011;163:80-82.

67. Hunter I, Ramanathan V, Balasubramanian P, Evans DA, Hardman JG, McCahon RA. Retention of laryngoscopy skills in medical students: a randomized, cross-over study of the Macintosh, A.P. Advance ${ }^{\mathrm{TM}}, \mathrm{C}-\mathrm{MAC}$ and Airtraq ${ }^{\circledR}$ laryngoscopes. Anesthesia. 2016;71(10):1191-1197.

68. Zaouter C, Calderon J, Hemmerling TM. Videolaryngoscopy as a new standard of care. Br J Anaesth. 2014;114(2):181-183.

69. Aziz MF, Brambrink AM, Healy DW, et al. Success of intubation rescue techniques after failed direct laryngoscopy in adults: a retrospective comparative analysis from the multicenter perioperative outcomes group. Anesthesiology. 2016;125(4):656-666.

70. Cook TM, Woodall N, Frerk C; Fourth National Audit Project. Major complications of airway management in the UK: results of the Fourth National Audit Project of the Royal College of Anesthetists and the Difficult Airway Society. Part 1: anesthesia. Br J Anaesth. 2011; 106(5):617-631.

71. El-Orbany M, Woehlck H, Salem MR. Head and neck position for direct laryngoscopy. Anesth Analg. 2011;113(1):103-109.

72. Behringer EC, Kristensen MS. Evidence for benefit versus novelty in new intubation equipment. Anesthesia. 2011;66 (Suppl 2):57-64.

73. Lyon RM, Perkins ZB, Chatterjee D, Lockey DJ, Russell MQ; Kent, Surrey \& Sussex Air Ambulance Trust. Significant modification of traditional rapid sequence induction improves safety and effectiveness of pre-hospital trauma anesthesia. Crit Care. 2015;19:134.

74. Marsch SC, Steiner L, Bucher E, et al. Succinylcholine versus rocuronium for rapid sequence intubation in intensive care: a prospective, randomized controlled trial. Crit Care. 2011;15(4):R199.

75. Natt BS, Malo J, Hypes CD, Sakles JC, Mosier JM. Strategies to improve first attempt success at intubation in critically ill patients. BrJ Anaesth. 2016;117 (Suppl 1):i60-i68.

76. Hypes CD, Stolz U, Sakles JC, et al. Video laryngoscopy improves odds of first attempt success at intubation in the ICU: a Propensity-matched analysis. Ann Am Thorac Soc. 2016;13(3):382-390.

77. Chhavi S, Abhyuday K, Parin L. Video laryngoscope as the new standard of care in trauma ED. Am J Emerg Med. 2016;34(7):1313-1314.

78. Sakles JC, Rodgers R, Keim SM. Optical and video laryngoscopes for emergency airway management. Intern Emerg Med. 2008;3(2): $139-143$.

79. Zaouter C, Calderon J, Hemmerling TM. Videolaryngoscopy as a new standard of care. Br J Anaesth. 2015;114(2):181-183.

80. Karl Storz GmbH \& Co. KG, Tuttlingen, Germany. Available from: http://www.karlstorz.de/cps/rde/xchg/SID-E5A329DA-B9AE794B/ karlstorz-en/hs.xsl/9549.htm. Accessed May 4, 2017.
Therapeutics and Clinical Risk Management

\section{Publish your work in this journal}

Therapeutics and Clinical Risk Management is an international, peerreviewed journal of clinical therapeutics and risk management, focusing on concise rapid reporting of clinical studies in all therapeutic areas outcomes, safety, and programs for the effective, safe, and sustained use of medicines. This journal is indexed on PubMed Central, CAS,

\section{Dovepress}

EMBase, Scopus and the Elsevier Bibliographic databases. The manuscript management system is completely online and includes a very quick and fair peer-review system, which is all easy to use. Visit http://www.dovepress.com/testimonials.php to read real quotes from published authors. 